DOI 10.37882/2223-2974.2020.10.26

\title{
ПРИОРИТЕТНЫЕ ФАКТОРЫ ПОВЫШЕНИЯ ЭФФЕКТИВНОСТИ ТРУДА ПЕРСОНАЛА ОРГАНИЗАЦИИ В УСЛОВИЯХ ЦИФРОВОЙ ЭКОНОМИКИ
}

\section{PRIORITY FACTORS OF INCREASING LABOR EFFICIENCY OF THE ORGANIZATION'S PERSONNEL IN THE DIGITAL ECONOMY}

\section{Ju. Panko}

Summary: In modern conditions, the transition to the digital economy is taking place all over the world, in Russia these processes are just beginning, at the same time, it becomes obvious that the priorities of the factors that affect the increase in the efficiency of the personnel of organizations are being revised. Presented in the article, the author's priority factors for increasing the efficiency of the organization's personnel in the digital economy will allow each organization to choose its own strategy for increasing labor productivity, based on the available opportunities, but the greatest effect will be achieved through the implementation of measures in all areas at once.

Keywords: digitalization, innovation, labor potential, personnel motivation, business processes, digital technologies.

\author{
Панько Юлия Владимировна \\ К.э.н., доцент, Российский университет транспорта, \\ 2. Москва. \\ panko_roat_dot@bk.ru
}

Аннотация: В современных условиях совершается переход к цифровой экономике во всем мире, в России данные процессы еще только начинаются, в тоже время становится очевидным то, что происходит пересмотр приоритетов факторов, влияющих на повышение эффективности труда персонала организаций. Представленная в статье авторская приоритетных факторов повышения эффективности труда персонала организации в условиях цифровой экономики позволит каждой организации выбирать свою стратегию повышения производительности труда, исходя из имеющихся возможностей, но наибольший эффект будет достигнут благодаря реализации мероприятий сразу по всем направлениям.

Ключевые слова: цифровизация, инновации, трудовой потенциал, мотивация персонала, бизнес-процессы, цифровые технологии.

номику как такой этап развития, на котором происходит перераспределение приоритетов для факторов повышения эффективности труда персонала организации, в связи с чем становится очевидной актуальность данной статьи.

Эффективность труда на предприятии считается динамичным показателем, который подвергается воздействию ряда факторов и играет значительную роль среди показателей эффективности общественного производства. Применяя этот показатель можно оценить эффективность работ как всего персонала, так и отдельного сотрудника. Поэтому перед собственниками и руководителями организаций всегда возникает вопрос о поиске путей повышения эффективности труда персонала [1]. Каждое предприятие разрабатывает конкретную программу развития трудового потенциала, которая должна обеспечить эффективное управление эффективностью труда. Ее разработка определенной степени зависит от факторов повышения эффективности труда персонала, которые способствуют ее изменению. Таким образом, повышение эффективности труда персонала организации - это сложный процесс, который требует благоприятной среды, достаточного профессионализма управленческих кадров и готовности самого персонала 
Таблица 1.

Систематизация приоритетных факторов повышения эффективности труда персонала организации

в условиях цифровой экономики (составлено автором по данным $[2,3,5]$

\begin{tabular}{|c|c|c|}
\hline Факторы & Цифровые изменения в глобальной экономике & Цифровые изменения в экономике России \\
\hline Структурные & $\begin{array}{l}\text { Доминирование 4-6-го и переход на 7-й технологический уклад; } \\
\text { высокая доля инновационных предприятий (от 60\%) }\end{array}$ & $\begin{array}{l}\text { Внедрение 4-го технологического уклада; рост доли инноваци- } \\
\text { онных предприятий, которые реально производят инновации }\end{array}$ \\
\hline Пространственные & $\begin{array}{l}\text { Стремительное развитие инновационного предприниматель- } \\
\text { ства на территориях со специфическим режимом (типа силико- } \\
\text { новых долин, технополисов, технопарков и т.д.) }\end{array}$ & $\begin{array}{l}\text { Стимулирование инновационного предпринимательства путем } \\
\text { развития сети индустриальных парков, регулирование деятель- } \\
\text { ности стартапов }\end{array}$ \\
\hline Отраслевые & $\begin{array}{l}\text { Эффективное взаимодействие человека, его знаний и интеллек- } \\
\text { та с роботизированными механизмами } \\
\text { Предложение видов услуг, ориентированных на формирование } \\
\text { новых потребностей человека }\end{array}$ & $\begin{array}{l}\text { Взаимодействие человека, его знаний и интеллекта с механиз- } \\
\text { мами, возможность производить роботизированные техноло- } \\
\text { гии } \\
\text { Предложение видов услуг, ориентированных на полное удов- } \\
\text { летворение потребностей человека }\end{array}$ \\
\hline Конкурентные & $\begin{array}{l}\text { Выработка радикальных (пионерных) и маркетинговых инно- } \\
\text { ваций в качестве новых форм конкурентной борьбы и завоева- } \\
\text { ния рынка }\end{array}$ & $\begin{array}{l}\text { Способность внедрять простые и улучшающие инновации, мар- } \\
\text { кетинговые инновации на основе добросовестной конкуренции }\end{array}$ \\
\hline Кадровые & $\begin{array}{l}\text { Ведущая ценность интеллекта человека, его организованности } \\
\text { и стрессоустойчивости }\end{array}$ & $\begin{array}{l}\text { Ведущая ценность интеллекта человека, его способности рабо- } \\
\text { тать в коллективе и взаимодействовать с руководством }\end{array}$ \\
\hline управленческие & $\begin{array}{l}\text { Корпоративно-индивидуализированный подход к всесторонней } \\
\text { мотивации персонала }\end{array}$ & Корпоративный подход к всесторонней мотивации персонала \\
\hline Орган & $\begin{array}{l}\text { Ведущая роль цифровизации на бизнес-процессы организаций } \\
\text { с контролем соблюдения прав субъектов хозяйствования и ра- } \\
\text { ботников }\end{array}$ & $\begin{array}{l}\text { Формирование основ цифровизации в отдельных отраслях эко- } \\
\text { номики с контролем соблюдения прав субъектов хозяйствова- } \\
\text { ния и работников }\end{array}$ \\
\hline Правовые & $\begin{array}{l}\text { Высокий уровень правовой культуры и защищенности персона- } \\
\text { ла в процессе использования цифровых технологий }\end{array}$ & $\begin{array}{l}\text { Рост уровня правовой культуры организаций в процессе исполь- } \\
\text { зования цифровых технологий }\end{array}$ \\
\hline Диалектические & $\begin{array}{l}\text { Обеспечение цифровой трансформации на принципах инклю- } \\
\text { зивного роста }\end{array}$ & $\begin{array}{l}\text { Постепенный переход от экстенсивных к интенсивным принци- } \\
\text { пам экономического роста }\end{array}$ \\
\hline Концептуальные & $\begin{array}{l}\text { Долгосрочная стратегия развития, ориентированная на цифро- } \\
\text { визацию экономики и инновации с интегральным эффектом }\end{array}$ & $\begin{array}{l}\text { Долгосрочная стратегия развития, ориентированная на эколо- } \\
\text { гические и социальные инновации, переход к цифровым техно- } \\
\text { логиям }\end{array}$ \\
\hline
\end{tabular}

эффективно использовать и развивать свой интеллектуально-трудовой потенциал.

Условно все факторы можно разделить на внутренние и внешние. Внутренними факторами считаются те, на которые предприятие может самостоятельно вливать. Например, продукция, ее качественные свойства, производственное оборудование, материалы, из которых изготавливается продукция, персонал и организация его труда и тому подобное. Внешние факторы, в свою очередь, находятся вне зоны контроля предприятия. Это прежде всего такие общегосударственные на экономические факторы, как политика, законы и подзаконные акты, рыночная инфраструктура, глобальные изменения в обществе, уровень обеспеченности природными ресурсами, экономическая интеграция и тому подобное. Учитывая, что предприятие не имеет компетенции законными способами влиять на внешние факторы, большое внимание организации уделяют изучению именно внутренних факторов.
Современный этап развития человечества является очень динамичным. Большое влияние оказывает цифровая трансформация. При таких условиях субъекты бизнеса, которые ориентированы на долгосрочную стратегию развития, вынуждены ориентироваться на элементы цифровой экономики и инновационную составляющую деятельности. Соответствие стратегии развития предприятия цифровой концепции бизнеса является основой для формирования эффективных и рациональных мер стимулирования работников к продуктивной деятельности с ориентацией на достижение корпоративных целей. В противном случае они рискуют потерять рыночные позиции в жестких условиях конкурентной борьбы за ресурсы, рынки сбыта, квалифицированные кадры. Поэтому любая организация обязательно должна учитывать цифровые трансформационные изменения в экономике [3].

Для российских предприятий их следует выделять по двум уровням: 
а) цифровой характер изменений на уровне экономики страны;

б) цифровой характер изменений на уровне глобальной экономики.

Поскольку наше государство отстает от ведущих стран по многим позициям, отдельные цифровые тренды могут определяться как новые для внутренней национальной среды, хотя они могут быть давно распространенными в других государствах. В то же время цифровой прорыв или поступательное инновационное развитие требует поочередного внедрения новейших технологий, касающихся различных сфер общественной и экономической жизни. В таблице 1 представлена авторская систематизация приоритетных факторов повышения эффективности труда персонала организации в условиях цифровой экономики, обусловленных основными инновационными изменениями в экономике, детерминирующими особенности социально-экономической мотивации персонала для каждого предприятия.

Определенные в таблице 1 инновационные изменения глобального и национального характера отражают разрывы экономики России с глобальными трендами, внедряемыми передовыми странами. Вместе с тем, современный мир очень разнообразен в плане социальноэкономического развития.
Таким образом, управление эффективностью труда персонала и разработка мероприятий по ее увеличению - важная задача, решать которую должна решать организация любой сферы деятельности. Понимание факторов, от которых зависит повышение эффективности труда, является необходимым условием обеспечения конкурентоспособности организации, поскольку существует очень много направлений повышения эффективности труда - от модернизации оборудования к мотивации работников. Представленная в статье авторская систематизация приоритетных факторов повышения эффективности труда персонала организации в условиях цифровой экономики позволит каждой организации выбирать свою стратегию повышения производительности труда, исходя из имеющихся возможностей и потребностей. При этом следует понимать, что максимальный эффект может быть достигнут в результате учета всех факторов воздействия и реализации мероприятий сразу по всем направлениям. Полагаем, если рассматривать вопрос повышения эффективности труда персонала через призму цифровых трансформаций в экономике России, то эту задачу нужно рассматривать с двух сторон не только инновационные изменения экономики оказывают влияние на практику мотивации в предпринимательской среде, но и его субъекты через мотивацию становятся основным двигателем инновационных изменений национальной экономики.

\section{ЛИТЕРАТУРА}

1. Захаров А.Н., Зверева И.А., Козлов В.А. Мотивация трудовых ресурсов в условиях цифровой экономики // РППЭ. 2018. №12 (98). С.251-259.

2. Кумаритова 3.А., Ситохова Т.Е. Повышение производительности труда в условиях цифровизации экономики России // Финансовые исследования. 2019. №4 (65). C.177-185.

3. Орехов В.Д., Мельник М.С., Причина О.С. Исследование новых тенденций и закономерностей воздействия цифровой экономики на производительность труда // Проблемы экономики и юридической практики. 2018. №2. С.20-25.

4. Петрова Н.П., Бондарева Г.А. Цифровизация и цифровые технологии в образовании // Мир науки, культуры, образования. 2019. №5 (78). С. $353-355$. doi: 10.24411/1991-5497-2019-00138.

5. Степанов 0.А. О важных аспектах подготовки кадров для развития цифровой экономики // Журнал российского права. 2018. №11 (263). С.106-111.

(с) Панько Юлия Владимировна (panko_roat_dot@bk.ru).

Журнал «Современная наука: актуальные проблемы теории и практики» 